\title{
O manejo florestal como estratégia para mitigar os impactos da exploração florestal
}

O objetivo do trabalho é avaliar o impacto da exploração madeireira na dinâmica florestal em uma área de floresta nativa manejada. Foi realizado o censo préexploratório dos indivíduos comerciais de diâmetro $=45 \mathrm{~cm}$ em duas unidades trabalho (UT), uma explorada e outra testemunha no ano de 2004 e em 2015 . Analisou-se o recrutamento e a mortalidade. Calculou-se a área aberta das trilhas, pátios e estradas secundárias através da confecção de mapas utilizando o no sistema de informação geográfica (SIG). Os índices da estrutura da floresta foram calculados em função da abundância, área basal, volume e áreas explorada e testemunha. $\mathrm{O}$ volume, área basal e mortalidade na área explorada foi menor que na área testemunha. 0 recrutamento foi de $23 \%$ na área explorada e $22 \%$ na área testemunha. A área impactada pelas trilhas de arraste primária e secundária foi de respectivos $6.135 \mathrm{~m}^{2}$ e $16.570 \mathrm{~m}^{2}$, enquanto na estrada secundária e no pátio de estocagem foi de $18.568 \mathrm{~m}^{2}$ e $2.874 \mathrm{~m}^{2}$. O planejamento da exploração florestal contribuiu para diminuir os danos nas espécies arbóreas de diâmetro $=$ $45 \mathrm{~cm}$.

Palavras-chave: Mortalidade; Recrutamento; Georreferenciamento.

\section{Forest management as a strategy to mitigate the impacts of logging}

The objective of this work is to evaluate the impact of logging on forest dynamics in a managed native forest area. Pre-exploratory census of commercial individuals $=45 \mathrm{~cm}$ in diameter was performed in two work units (TU), one explored and the other witness in 2004 and 2015. Recruitment and mortality were analyzed. The open area of the trails, courtyards and secondary roads was calculated by making maps using the geographic information system (GIS). Forest structure indices were calculated as a function of abundance, basal area, volume and areas explored and control. The volume, basal area and mortality in the explored area was lower than in the control area. Recruitment was $23 \%$ in the exploited area and $22 \%$ in the control area. The area impacted by the primary and secondary drag trails was $6,135 \mathrm{~m}^{2}$ and $16,570 \mathrm{~m}^{2}$, while the secondary road and stockyard were $18,568 \mathrm{~m}^{2}$ and $2,874 \mathrm{~m}^{2}$. Planning of forest exploitation contributed to reduce damage to tree species $=45 \mathrm{~cm}$ in diameter.

Keywords: Mortality; Recruitment; Georeferencing.

Topic: Ciências Florestais

Reviewed anonymously in the process of blind peer
Received: 02/10/2019

Approved: 26/11/2019
Larissa Martins Barbosa D'Arace (10) Embrapa Amazônia Oriental, Brasil http://lattes.cnpq.br/1315133297466306 http://orcid.org/0000-0002-8533-555X larissamartins350@gmail.com

\section{Lailson Dantas Silva (D)}

Universidade Estadual do Maranhão, Brasil

http://lattes.cnpq.br/3000143824915035

http://orcid.org/0000-0002-2244-9656

lailson.ef@hotmail.com

Jaqueline Macedo Gomes (iD

Universidade Estadual da Região Tocantina do Maranhão, Brasil

http://lattes.cnpq.br/6999782343980504

http://orcid.org/0000-0001-9506-6747

jaquelinemacedogomes@hotmail.com
Nisangela Severino Lopes Costa (iD)

Universidade Estadual da Região Tocantina do

Maranhão, Brasil

http://lattes.cnpq.br/9564840904035403

http://orcid.org/0000-0003-4797-4649

nisangela.lopes@hotmail.com

Bruna da Silva Casseb (iD)

Universidade Federal Rural da Amazônia, Brasil

http://lattes.cnpq.br/3453572843307824

http://orcid.org/0000-0001-5778-8298

brunacasseb@hotmail.com

Mario Lima dos Santos (ii

Universidade de Brasília, Brasil

http://lattes.cnpq.br/2198880214852835

http://orcid.org/0000-0003-1679-9796

mariolimaeng@gmail.com

\begin{abstract}
Eduardo Saraiva da Rocha (iD
Universidade Federal Rural da Amazônia

Brasil

http://lattes.cnpq.br/4485232670269332

http://orcid.org/0000-0003-4971-6969

engftalsaraiva@yahoo.com.br
\end{abstract}

Maria de Nazaré Martins Maciel (ic

Universidade Federal Rural da Amazônia,

Brasil

http://lattes.cnpq.br/0462734548870684

http://orcid.org/0000-0002-6458-2076

nazamaciel@yahoo.com.br

Lucas José Mazzei de Freitas (ic

Embrapa Amazônia Oriental

http://lattes.cnpq.br/5795318631773924

http://orcid.org/0000-0002-1757-9472

lucas.mazzei@embrapa.br

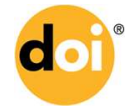

DOI: 10.6008/CBPC2179-6858.2019.006.0004
Referencing this:

D'ARACE, L. M. B.; SILVA, L. D.; GOMES, J. M.; COSTA, N. S. L.; CASSEB, B. S.; SANTOS, M. L.; ROCHA, E. S.; MACIEL, M. N. M.; FREITAS, L. J. M.. O manejo florestal como estratégia para mitigar os impactos da exploração florestal. Revista Ibero Americana de Ciências Ambientais, v.10, n.6, p.32-42, 2019. DOI: http://doi.org/10.6008/CBPC21796858.2019 .006 .0004 


\section{INTRODUÇÃO}

O manejo florestal é utilizado como estratégia para exploração econômica dos recursos florestais buscando manter a conservação do ecossistema. Assim, essa prática busca desenvolver tecnologias que possibilitem a redução dos danos da exploração, além de acelerar a recuperação da floresta com tratamentos silviculturais pós-exploratórios. A lei no 11.284, define manejo florestal sustentável como:

A administração da floresta para a obtenção de benefícios econômicos, sociais e ambientais, respeitando-se os mecanismos de sustentação do ecossistema objeto do manejo e considerando-se, cumulativa ou alternativamente, a utilização de múltiplas espécies madeireiras, de múltiplos produtos e subprodutos não madeireiros, bem como a utilização de outros bens e serviços de natureza florestal. (BRASIL, 2006).

A partir da definição de manejo florestal sustentável pode-se inferir que o mesmo é a melhor maneira para a exploração racional da floresta, garantindo a produtividade e recursos para as gerações futuras. A exploração quando executada de forma predatória ou não planejada ocasiona mudanças na dinâmica de crescimento e no processo sucessional das florestas tropicais dificultando a regeneração natural e a manutenção da floresta (FRANCEZ et al., 2013). Para minimizar os danos da exploração Castro et al. (2018) destacam a importância da exploração planejada, pois os danos causados por esta atividade não são significativos, reduzindo os impactos e mantendo a alta diversidade na área de manejo.

Dessa forma a exploração seletiva é uma prática adotada para conservar a floresta e garantir o uso dos recursos, no entanto, são poucas as evidências científicas que comprovem a sustentabilidade desta prática (GATTI et al., 2015). Sendo necessário intensificar pesquisas que avaliem a longo prazo os efeitos da exploração florestal na estrutura e dinâmica da florestal, desenvolvendo tecnologias para redução de danos, de forma que atenta a sustentabilidade para ter o equilíbrio entre ambiental, econômico e social.

O planejamento das atividades de colheita diminui custos da exploração e os impactos ambientais negativos, garantindo a manutenção da biodiversidade e conservação dos ecossistemas, permitindo que a floresta se recupere em menor tempo (HIRAI et al., 2012; TAFFAREL et al., 2014). Nas atividades do manejo florestal, os danos causados pela exploração na floresta remanescente devem ser detectados com o objetivo de eliminá-los ou reduzi-los ao mínimo, evitando prejuízo às produções futuras e danos ecológicos na vegetação (MARTINS et al, 2003). Assim, torna-se fundamental avaliar os impactos da exploração na floresta remanescente no que se refere ao seu crescimento, recrutamento, mortalidade e estoque madeireiro para futuras colheitas.

A avaliação de danos sobre a floreta pode ser feita utilizando a tecnologia GPS e o sensoriamento remoto (MARVIN et al., 2016), porém, está tecnologia ainda precisa ser implementada como ferramenta de otimização em empresas florestais na Amazônia brasileira (SILVA et al., 2018). Utilizando um Sistemas de Informações Geográficas (SIG) no processamento de dados obtidos pelo inventário florestal torna-se possível obter informações úteis ao manejo florestal de precisão, aumentando a eficiência das operações florestais e minimização dos impactos à biodiversidade. Tais informações contribuem para um melhor planejamento das atividades a serem executadas em uma Área de Manejo Florestal (AMF), utilizando mapas georreferenciados (CONDÉ, 2011). 
O uso do Geoprocessamento, conciliado com o uso do sistema de posicionamento por satélite (GPS) e de um ambiente de Sistema de Informações Geográficas (SIG), é uma importante ferramenta no que tange à precisão do mapeamento e à localização das árvores da floresta, assim como na maior capacidade visual para a tomada de decisões sobre as intervenções silviculturais e de exploração, que tenham por objetivo a sustentabilidade da produção e a diminuição dos impactos pós-exploração. Com isso este trabalho teve como objetivo avaliar o impacto da exploração madeireira na dinâmica florestal em uma área de floresta nativa manejada.

\section{MATERIAIS E MÉTODOS}

\section{Área de estudo}

A área experimental está localizada na Fazenda Rio Capim $\left(48^{\circ} 28^{\prime}-48^{\circ} 54^{\prime} \mathrm{W}\right.$ e $\left.3^{\circ} 18^{\prime}-3^{\circ} 50^{\prime} \mathrm{S}\right)$, no município de Paragominas, sudeste do Estado do Pará. O clima da região é do tipo Aw, segundo a classificação de Köppen (ALVARES et al., 2013). O relevo da região é plano a levemente ondulado com altitude média em torno de $200 \mathrm{~m}$. Os Solos são do tipo latossolo amarelo com alto grau de intemperismo (RODRIGUES et al., 2003). A floresta é do tipo floresta ombrófila densa de terra firme (IBGE, 2012).

\section{Coleta de dados}

Para a coleta de dados foram selecionados 50 hectares de uma Unidade de Trabalho (UT) em uma Unidade de Produção Anual (UPA) da propriedade, explorada em agosto de 2004. Em 2004 foi realizado um inventário $100 \%$ de todos os indivíduos com diâmetro à altura do peito (DAP) maior ou igual a $45 \mathrm{~cm}$ em toda a UT (100 ha), das 144 espécies comercializadas pela empresa, sendo selecionados para corte indivíduos com DAP $\geq 55 \mathrm{~cm}$. Em 2015 foi feito um novo censo nessa área e foram inventariados 50 hectares da floresta em cada UPA, onde foram levantadas todas as espécies de DAP $\geq 45 \mathrm{~cm}$.

O estudo foi desenvolvido na UT 14 da UPA 7 submetida a exploração florestal madeireira e na UT 8 da UPA 8, área não explorada (Testemunha). Com este levantamento, foram localizadas e selecionadas as árvores a serem exploradas, as remanescentes e as de estoque para se obter uma estimativa de volume comercial utilizável por árvore e por unidade de área.

A partir de trilhas de orientação cada árvore foi numerada, plaqueteada e foram levantados os nomes vulgares por parabotânicos, coordenadas cartesianas (distancia x, y), diâmetro a altura do peito (DAP), altura, qualidade de fuste, de copa e presença de cipós. Após a escolha das árvores a serem exploradas, foram confeccionados mapas de cada UT, onde apresentam a localização, numeração e nome vulgar dos indivíduos a serem exploradas, e os remanescentes (em cores diferenciadas), além do planejamento das estradas secundárias, pátios de estocagem (Tabela 1). No sistema de exploração de impacto reduzido realizado na área de estudo se utilizou o trator florestal Skidder, para o arraste do feixe de toras, da área de corte até o pátio temporário (FERREIRA, 2005). 
Tabela 1: Anos dos inventários, atividade e variáveis coletadas.

\begin{tabular}{|l|l|l|}
\hline Ano & Atividade & Variáveis coletadas \\
\hline 2004 & Inventário $100 \%$ pré exploratório & DAP, nome da espécies e as informações de - \\
\hline 2015 & Inventário 50\% pós exploratório & $\begin{array}{l}\text { DAP, nome da espécie, coordenadas geográficas, qualidade de fuste; e seu } \\
\text { aproveitamento quando morta, não encontrada e corte. }\end{array}$ \\
\hline
\end{tabular}

\section{Análise dos dados}

\section{Georreferenciamento dos dados no sistema de informação geográfica (SIG)}

Inicialmente as árvores foram mapeadas a partir das coordenadas obtidas por meio de GPS de navegação modelo Garmin GPSMap 76CSx. Posteriormente foram atribuídos os dados do inventário florestal em planilha eletrônica, e esta foi convertida em dados vetoriais. Todos os pontos que foram coletados da área explorada foram projetados no sistema de coordenadas Universal Transversa de Mercator (UTM), zona 22 S e Sirgas 2000.

Os mapas das unidades de trabalho que estavam impressos, foram digitalizados e transformados em matrizes georreferenciadas (raster) no sistema de coordenada em UTM, e as coordenadas cartesianas (X e Y) dos indivíduos foram corrigidas de modo que sua localização fosse coincidente com a localização obtida em campo no segundo inventário pelo sistema de informação geográfica no programa QGIS 2.18.

A partir da matriz georreferenciada, foi gerada um arquivo vetorial, onde foram realizadas as edições das trilhas de arraste primária, secundária, estrada secundária e pátios de estocagens. Foram realizados cálculo da área aberta estimando o comprimento total das trilhas de arraste primária e secundária, estrada secundária e a área total de cada pátio de estocagem no Q-gis. A área aberta das trilhas de arraste primária e secundária e estrada secundária foi obtida utilizando-se equação:

$$
A=\text { Comprimento } \times \text { Largura }
$$

\section{Estrutura florestal}

Foi realizada mediante comparações entre os dados obtidos entre os inventários realizados nos anos de 2004 (antes da exploração) e 2015 (após a exploração). Em 50 hectares na área explorada e na área testemunha. Os parâmetros calculados e analisados foram o volume (V), área basal (G) e abundância (Ab), taxa de mortalidade (TM) e taxa de recrutamento (TR) de acordo com as fórmulas abaixo:

\section{Abundância}

$$
A b=\frac{N \text { árvores }}{\text { área }}
$$

Onde: $\mathrm{Ab}=\mathrm{Abundância}\left(\right.$ (árv.ha ${ }^{-1}$ )

\section{Área basal}

$$
\begin{gathered}
g i=\left(\pi * \frac{D A P^{2}}{40000}\right) \\
G=\sum g i
\end{gathered}
$$


gi = área da seção transversal individual; $\mathrm{p}=\mathrm{pi}$ (constante matemática); $\mathrm{DAP}=$ diâmetro à altura do peito em $\mathrm{cm}$; $\mathrm{G}=$ área basal em $\mathrm{m} 2 /$ ha

\section{Volume}

$$
\begin{array}{r}
V=10^{\wedge}(-2,96+1,93 * \log 10(D A P \mathrm{~cm})) \quad(\mathrm{Eq} 4) \\
\text { Onde: } \mathrm{V}=\text { volume }\left(\mathrm{m}^{3} \cdot \mathrm{ha}^{-1}\right) ; \mathrm{DAP}=\text { diâmetro a altura do peito }
\end{array}
$$

\section{Taxa de mortalidade}

A taxa de mortalidade corresponde aos indivíduos de espécies comerciais com DAP $\geq 45 \mathrm{~cm}$ que tiveram algum tipo de aproveitamento ou nenhum aproveitamento e não encontrados. A mortalidade pode ser por motivos naturais ou em função da exploração, ou seja, a ação antrópica, os indivíduos explorados não foram considerados mortos. A taxa de mortalidade foi calculada pela seguinte equação:

$$
M(\%)=\frac{n i}{N i} * 100
$$

Onde: $\mathrm{M}$ = taxa de mortalidade; $\mathrm{ni}$ = número de indivíduos que morreram entre duas medições; $\mathrm{Ni}=$ é o número de indivíduos vivos da medição anterior.

Foram analisados das três espécies mais exploradas o volume, área basal, número de árvores absolutos e por hectare.

\section{Efeito da exploração na mortalidade de árvores}

No estudo considerou se dois fatores que causaram a mortalidade: atividade da exploração florestal madeireira que ocasionou a queda de árvores e motivos naturais. O efeito da exploração florestal na moralidade foi analisada a partir da relação entre árvores vivas e mortas com as trilhas de arraste, pátio de estocagem, estrada secundária, e a partir dessa análise é possível saber se houve influência da exploração na mortalidade das árvores.

Para avaliar o efeito da exploração na mortalidade foram calculadas as distâncias das árvores mortas em relação as árvores exploradas (toco), as trilhas de arraste, a estrada secundária e aos pátios de estocagem no SIG. Posteriormente realizou-se análise estatística no software $\mathrm{R}$ utilizando-se a regressão logística, assim calculada:

$$
\begin{gathered}
p(t)=1 /(1+e-t) \\
\text { ou } \quad \text { (Eq 6) } \\
y p(Y)=1 /(1+e-(\beta o+\beta 1 x 1+\beta 2 x 2+\ldots+\beta n x n))
\end{gathered}
$$

Onde: $\mathrm{Y}=$ a variável resposta, que pode assumir os valores 0 ou $1 ; \mathrm{Xn}=0$ vetor representando as variáveis regressoras.

\section{Taxa de recrutamento}

A taxa de recrutamento refere-se aos indivíduos que na medição anterior, ou seja, em 2004 possuíam diâmetro menor que o nível de inclusão na ocasião de monitoramento e que, no segundo censo no ano de 2015 apresentou DAP $\geq 45 \mathrm{~cm}$. A taxa de recrutamento pode ser calculada pela seguinte equação:

$$
R(\%)=\frac{n i}{N i} * 100
$$


Onde: $\mathrm{R}$ = taxa de recrutamento; $\mathrm{ni}$ = número de indivíduos que recrutaram entre duas medições; $\mathrm{Ni}=$ número de indivíduos vivos da medição anterior.

Foi calculado a área basal (G), taxa de mortalidade e recrutamento para a comunidade na área testemunha e na área explorada e para as três espécies mais exploradas na área explorada

\section{RESULTADOS E DISCUSSÃO}

\section{Estrutura da floresta}

Das árvores mortas na área explorada 49 indivíduos tiveram aproveitamento para carvão ou serraria e na área não explorada 73 indivíduos foram aproveitados. O número de indivíduos remanescentes foi maior na área não explorada devido a exploração florestal na área que ocorreu exploração.

Tabela 2: Número de indivíduos comerciais cortados (explorados), mortos de forma natural ou pela ação antrópica que tiveram algum tipo de aproveitamento ou não e os que não foram encontrados (NE), vivas remanescentes e recrutas e seus respectivos volumes na UPA 7 UT 14 e UPA 8 UT 8.

\begin{tabular}{|c|c|c|}
\hline \multicolumn{3}{|l|}{ UPA 7 UT 14 (área explorada) } \\
\hline Variável & $\mathrm{N}^{\circ}$ de indivíduos & Volume/ ha $\left(\mathrm{m}^{3} / \mathrm{ha}\right)$ \\
\hline Vivas antes da exploração & 754 & 59,5 \\
\hline Corte & $344(\mathrm{DAP} \geq 55 \mathrm{~cm})$ & 29,2 \\
\hline Mortos & 108 (49 aproveitamentos ou $59 \mathrm{NE}$ ) & 7,2 \\
\hline Vivas remanescentes & 302 & 26,5 \\
\hline Vivas recrutas & 174 & 11,1 \\
\hline Remanescentes mais recrutas & 476 & 37,7 \\
\hline \multicolumn{3}{|l|}{ UPA 8 UT 8 (não explorada) } \\
\hline Variável & $\mathrm{N}^{\circ}$ de indivíduos & Volume/ ha $\left(\mathrm{m}^{3} / \mathrm{ha}\right)$ \\
\hline Vivas antes do período & 701 & 59,2 \\
\hline Corte & 0 & 0 \\
\hline Mortos & 116 (73 - aproveitamento ou $43 \mathrm{NE}$ ) & 9,1 \\
\hline Vivas remanescentes & 585 & 56,8 \\
\hline Vivas recrutas & 168 & 8,34 \\
\hline Remanescentes mais recrutas & 753 & 65,1 \\
\hline
\end{tabular}

Segundo Condé (2011) em um estudo sobre a avaliação dos impactos na vegetação após a exploração madeireira em floresta ombrófila densa de terra firme no município de Caracaraí/RR a intensidade média de exploração de 3 árvores comerciais extraídas por hectare (DAP > $50 \mathrm{~cm}$ ), correspondendo as médias de 18,66 $\mathrm{m}^{3}$ /ha de volume comercial e $34,04 \mathrm{~m}^{3}$ /ha de volume total, foram observadas no presente estudo, as seguintes médias: 15,0 árvores danificadas/árvore colhida/ha e 12 árvores mortas/árvore colhida/ha.

Os desperdícios de madeira pode ser definido simplesmente como a diferença entre a totalidade do volume comercial de madeira que poderia ter sido retirado da floresta e o volume retirado na exploração em questão. Existem muitas práticas que originam o desperdício na exploração, dentre as quais, citamos: (a) toras cortadas não encontradas pelas equipes de arraste ou simplesmente deixadas na floresta devido a práticas inadequadas de corte, que fizeram com que as toras rachassem durante a queda; (b) toras esquecidas nos pátios de estocagem; (c) desperdícios de madeira provocados por tocos da exploração muito altos ou devido a práticas inadequadas de traçamento das toras (LENTINI et al., 2015). No presente trabalho foram 59 indivíduos não encontrados na área explorada, porém caso não essa área não fosse explorada a partir de um plano de manejo florestal esse desperdício seria ainda maior devido à falta de planejamento.

Após 11 anos da colheita de madeira (2004 a 2015), ocorreu uma redução na abundância de 33,33\% 
(15 árv.ha-1 para 10 árv.ha-1), volume de $36,64 \%\left(59,5 \mathrm{~m}^{3} \cdot \mathrm{ha}^{-1}\right.$ para $\left.37,7 \mathrm{~m}^{3} \cdot \mathrm{ha}^{-1}\right)$ e área basal 36,21\% (5,8 $\mathrm{m}^{2}$.ha-1 para $3,7 \mathrm{~m}^{2}$.ha $\left.{ }^{-1}\right)$. Na área testemunha em 2004 foram registradas 14 árv/ha, com um volume médio de 59,2 $\mathrm{m}^{3} /$ ha e área basal de 5,8 $\mathrm{m}^{2} / \mathrm{ha}$. Já em 2015 onze anos após foram registrados 15 árv/ha com um volume total de $65,1 \mathrm{~m}^{3} / \mathrm{ha}$ e área basal total de $6,3 \mathrm{~m}^{2} /$ ha (Tabela 3 ).

Tabela 3: Abundância (Árv.ha-1), área basal $\left(\mathrm{m}^{2} \cdot\right.$ ha $\left.\mathrm{a}^{-1}\right)$ e volume $\left(\mathrm{m}^{3} \cdot h \mathrm{a}^{-1}\right)$ da área explorada e não explorada nos anos de 2004 e 2015 na Fazenda Rio Capim, no município de Paragominas (PA), sudeste do estado do Pará.

\begin{tabular}{|c|c|c|c|c|c|c|}
\hline & $\begin{array}{l}\mathbf{N}^{\circ} \text { de } \\
\text { ind. }\end{array}$ & $\begin{array}{l}\text { Ab } \\
\text { (árv.ha-1) }\end{array}$ & $\begin{array}{l}\text { Vol } \\
\left(\mathrm{m}^{3}\right)\end{array}$ & $\begin{array}{l}\text { Vol/ha } \\
\left(\mathrm{m}^{3} \cdot \mathrm{ha}^{-1}\right)\end{array}$ & $\begin{array}{l}G \\
\left(m^{2}\right)\end{array}$ & $\begin{array}{l}\text { G (m². ha- } \\
\text { 1) }\end{array}$ \\
\hline \multicolumn{7}{|l|}{ Área Explorada (UPA 7 UT 14) } \\
\hline Antes da exploração (2004) & 754 & 15 & 2974,4 & 59,5 & $\begin{array}{l}288 \\
4\end{array}$ & 5,8 \\
\hline $\begin{array}{l}\text { Após a Exploração (2015) (Soma de recrutas mais } \\
\text { remanescentes) }\end{array}$ & 476 & 10 & 1883,2 & 37,7 & $\begin{array}{l}183 \\
1\end{array}$ & 3,7 \\
\hline \multicolumn{7}{|l|}{ Área Testemunha (UPA 8 UT8) } \\
\hline Antes da Exploração (2004) & 701 & 14 & 2962 & 59,2 & $\begin{array}{l}288 \\
3\end{array}$ & 5,8 \\
\hline $\begin{array}{l}\text { Após a Exploração (2015) (Soma de recrutas mais } \\
\text { remanescentes) }\end{array}$ & 753 & 15 & 3257 & 65,1 & $\begin{array}{l}317, \\
3\end{array}$ & 6,3 \\
\hline
\end{tabular}

\section{Taxa de mortalidade e recrutamento}

A taxa de mortalidade na área explorada foi de $14,32 \%$, isso corresponde a 1,3\% por ano, enquanto que a taxa de recrutamento foi de $23,01 \%$ no período, representando $2,09 \%$ por ano. Na área testemunha a taxa de mortalidade foi de $16,55 \%$ no período correspondendo a 1,5\% por ano, já a taxa de recrutamento foi de $22,31 \%$ no período e de $2,03 \%$ por ano. Tanto na área explorada quanto na área não explorada a taxa de recrutamento foi maior que a taxa de mortalidade, porém a área explorada teve uma taxa de mortalidade menor e uma taxa de recrutamento maior (Tabela 4).

Tabela 4: Taxa de mortalidade e recrutamento no período de 11 anos e por ano na Fazenda Rio Capim, no município de Paragominas (PA), sudeste do estado do Pará.

\begin{tabular}{|l|l|l|}
\hline Área explorada & & \\
\hline Taxa de Mortalidade & $14,32 \%$ & $1,3 \%$. ano ${ }^{-1}$ \\
\hline Taxa de Recrutamento & $23,01 \%$ & $2,09 \%$. ano $^{-1}$ \\
\hline Área não explorada & & \\
\hline Taxa de Mortalidade & $16,55 \%$ & $1,5 \%$. ano ${ }^{-1}$ \\
\hline Taxa de Recrutamento & $22,31 \%$ & $2,03 \%$. ano $^{-1}$ \\
\hline
\end{tabular}

$\mathrm{Na}$ área explorada o volume total de árvores que morreram foi de $7,2 \mathrm{~m}^{3}$.ha e que recrutaram foi de $11,1 \mathrm{~m}^{3}$.ha, já na área testemunha o volume total de árvores mortas foram de $9,10 \mathrm{~m}^{3} /$ ha que recrutaram foi de $8,34 \mathrm{~m}^{3} / \mathrm{ha}$. Valores altos de mortalidade são observados nos primeiros anos após intervenções, e tendem a se equilibrar com o tempo (GRAAF et al., 1999; COSTA et al., 2002). De acordo com Nascimento et al. (2013), em ambientes com histórico de perturbação, a taxa de recrutamento tem um incremento exponencial no tempo, e, após um ápice de rendimento em recrutamento, esta taxa tem um crescimento menor ao longo do tempo de recuperação. Os resultados observados demonstram um balanço positivo entre ingresso e mortalidade e semelhantes as taxas observadas na área testemunha, onde considera-se que tenha um equilíbrio.

Silva et al. (1995) encontraram taxas de mortalidade na floresta Nacional do Tapajós de 2,6, 2,4 e 
2,2\%. ano ${ }^{-1}$ para cinco, seis e onze anos pós colheita, respectivamente. No presente estudo a taxa de mortalidade foi de $1,3 \%$. ano ${ }^{-1}$ onze anos após a exploração floresta e de $2,03 \%$. ano ${ }^{-1}$ na área não explorada.

\section{Georreferenciamento dos dados no sistema de informação geográfica (SIG)}

A estrada secundária foi a que apresentou maior área de 18.56,7 $\mathrm{m}^{2}$ e a trilhas de arraste primária menor área de $6.135,5 \mathrm{~m}^{2}$, onde a estradas secundárias provocaram maior impacto na floresta em relação as trilhas de arraste primária (Tabela 5).

Tabela 5: Comprimento, largura e área das trilhas de arraste primarias e secundarias e das estradas secundárias em 50ha na área explorada na Fazenda Rio Capim, no município de Paragominas (PA), sudeste do estado do Pará.

\begin{tabular}{|l|l|l|l|}
\hline & Comprimento $(\mathrm{m})$ & Largura $(\mathrm{m})$ & Área \\
\hline Trilhas de arraste primária & $1.022,6 \mathrm{~m}$ & $3,5 \mathrm{~m}$ & $6.135,4 \mathrm{~m}^{2}$ \\
\hline Trilhas de arraste secundária & $4.734,3 \mathrm{~m}$ & $3,5 \mathrm{~m}$ & $16.570,2 \mathrm{~m}^{2}$ \\
\hline Estrada secundária & $5.305,4 \mathrm{~m}$ & $6 \mathrm{~m}$ & $18.568,7 \mathrm{~m}^{2}$ \\
\hline Total & $11.062,2 \mathrm{~m}$ & $13 \mathrm{~m}$ & $41.274,2 \mathrm{~m}^{2}$ \\
\hline
\end{tabular}

O pátio 1 foi o que apresentou maior área com 1.119,5 $\mathrm{m}^{2}$, enquanto que o pátio 3 foi o que apresentou menor área com 540,7 m², os demais pátios 2 e 4 apresentaram áreas de 547,2 $\mathrm{m}^{2}$ e 667,4 m², totalizando de $2.874,8 \mathrm{~m}^{2}$. A área do pátio 1 pode estar associado ao planejamento incorreto, já que o número de árvores dentro e próximo a esse pátio foram os mesmos encontrados nos outros pátios, esse pátio causou maior dano, pois houve uma maior abertura de área na floresta.

A figura 1 ilustra a espacialização das trilhas de arraste, pátios de estocagem, estrada secundária, localização das árvores vivas, mortas e os tocos na em 50 ha da UPA 7 U14. Apesar de ter muitos tocos distribuídos na área, porém as árvores vivas são mais abundantes. As árvores mortas, tocos, árvores vivas estão distribuídas em toda a área. Com o planejamento da exploração florestal é possível identificar e localizar os indivíduos vivos, mortos, toco e as trilhas de arraste, estradas e pátios, além disso possibilita análises de estoque madeiro, monitoramento e futuras colheitas.

Após vários anos de exploração, onde a maioria da paisagem florestal já foi alterada devido os processos físicos e biológicos que ocorrem, dessa forma essas estradas, trilhas e pátios já foram cobertas pela vegetação dificultando a sua localização, porém com um mapa dessa área georreferenciado, a sua localização é facilitada.

Condé (2011) em seu trabalho em constatou que em relação às trilhas de arraste (principal e secundária), para cada árvore extraída 6 árvores foram danificadas e outras 6 foram mortas devido a construção de trilhas de arraste. No presente estudo mostra que as estradas secundarias causaram maiores impactos na exploração florestal devido apresentaram maior área e conforme a equação logística mostrou que quanto mais próximo as estradas secundárias maior a chance das árvores estarem mortas. Já as trilhas de arraste tiveram menor impacto na exploração florestal, pois conforme os resultados da equação logística mostrou que as trilhas de arraste primária e secundária não influenciou na mortalidade das árvores a partir de $45 \mathrm{~cm}$ de diâmetro. 


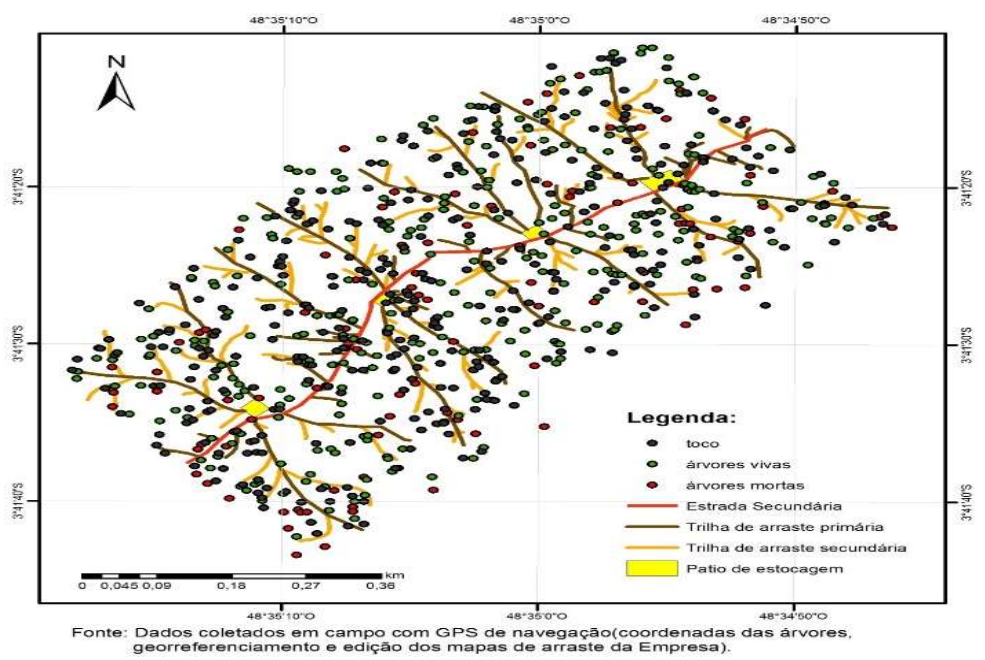

Figura 1: Mapa de corte/arraste de exploração com a localização dos tocos, árvores vivas remanescentes, mortas, estrada secundária, trilha de arraste primária, trilha de arraste secundária e pátios de estocagem em 50ha na área explorada na Fazenda Rio Capim, no município de Paragominas (PA), sudeste do estado do Pará.

\section{Efeito da exploração na mortalidade de árvores}

O efeito foi apenas na relação da mortalidade com a estrada secundária e do pátio com as árvores vivas, dessa forma é possível afirmar que: quanto mais próxima da estrada secundária mais chance de estar morta; quanto mais próxima do pátio mais chance de estar viva (Tabela 6). Não foi observado efeito entre as distancias das árvores vivas para as trilhas de arraste primária, secundária, para os tocos e para o pátio de estocagem.

Tabela 6: Resultados da regressão logística entre as variáveis distância com árvores vivas e mortas no período da área explorada na Fazenda Rio Capim, no município de Paragominas (PA), sudeste do estado do Pará.

\begin{tabular}{|l|l|l|}
\hline Variáveis & Parâmetro & $|z|$ \\
\hline Distância para o pátio & -0.011457 & $0.009543 * *$ \\
\hline Distância da trilha de arraste primária & 0.006075 & 0.334943 \\
\hline Distância da trilha de arraste secundária & 0.010357 & 0.130266 \\
\hline Distância para a estrada secundária & 0.010357 & $0.013781 *$ \\
\hline Distância para o toco & -0.008060 & 0.504056 \\
\hline
\end{tabular}

Onde: $|z|$ = nível de significância.

Apesar do número de remanescentes ser menor na área explorada devido a exploração, ou seja, 6 árv.ha' e a testemunha com 12 árv.ha', porém comparando as duas áreas (testemunha e explorada) acreditase que o impacto da exploração não foi severo na mortalidade das árvores com diâmetro maior ou igual a 45 $\mathrm{cm}$, pois a mortalidade na área testemunha foi maior que a área explorada, além de não haver relação das distâncias das árvores mortas com as trilhas, pátios e toco.

Conforme Pinto (2000), Pinto et al. (2002) os danos causados à vegetação adulta numa área explorada na Amazônia Ocidental, encontraram apenas 8\% de árvores danificadas, entre tronco e copa. Essas são percentagens realmente baixas e que tal resultado ocorreu em função, principalmente, do planejamento das operações de pré-exploração, corte de cipós, abertura das trilhas de arraste e direcionamento de queda de árvores. Isso pode ser observado no presente estudo, pois a mortalidade entre a área explorada e área não explorada foram próximas mostrando a eficiência do manejo florestal que tem como diretrizes o planejamento antes, durante e após a exploração florestal. 
Entre as espécies mais exploradas as que mais se destacaram foram a Manilkara elata (Allemão ex Miq.) Monach com 97 árvores exploradas em média foram exploradas 2 árv/ha, obtendo um volume de 10,04 $\mathrm{m}^{3} /$ ha e área basal de 0,98 $\mathrm{m}^{2} /$ ha, Manilkara paraenses (Huber) Standll com 25 árvores exploradas com um volume de $1,8 \mathrm{~m}^{3} /$ ha e área basal de $0,18 \mathrm{~m}^{2} /$ ha e Pseudopiptadenia suaveolens (Miq.) J.W. Grimes com o mesmo número de árvores exploradas que a Manilkara paraenses (Huber) Standll, porém com um volume de $1,81 \mathrm{~m}^{3} /$ ha e área basal de $0,17 \mathrm{~m}^{2} /$ ha (Tabela 7).

Tabela 7: As 3 espécies arbóreas comerciais com DAP $\geq 55 \mathrm{~cm}$ mais exploradas e seus respectivos número de indivíduos, volume absoluto e por hectare e área basal absoluta e por hectare na área de estudo.

\begin{tabular}{|c|c|c|c|c|c|c|}
\hline Nome cientifico & Nome vulgar & № ind. & $V\left(m^{3}\right)$ & $\begin{array}{l}\text { Vol } \\
\left(m^{3} \cdot h a^{-1}\right)\end{array}$ & $G\left(m^{2}\right)$ & $\begin{array}{l}\mathbf{G} \\
\left(m^{2} . h a^{-1}\right)\end{array}$ \\
\hline Manilkara elata (Allemão ex Miq.) Monach & Maçaranduba & 97 & 501,9 & 10,04 & 49,0 & 1 \\
\hline Manilkara paraensis (Huber) Standl. & Maparajuba & 25 & 93,3 & 1,8 & 9,0 & 0,18 \\
\hline Pseudopiptadenia suaveolens (Miq.) J.W. Grimes & Timborana & 25 & 90,4 & 1,8 & 8,70 & 0,17 \\
\hline
\end{tabular}

\section{CONCLUSÕES}

Com as técnicas de manejo florestal é possível mitigar os impactos da exploração florestal, pois o planejamento da exploração florestal contribui para diminuir os danos nas espécies arbóreas de diâmetro $\geq$ $45 \mathrm{~cm}$, já que após 11 anos da exploração florestal a área explorada apresentou maior taxa de recrutamento em relação a uma área não explorada, além disso as taxas de mortalidade entre as áreas exploradas e não exploradas foram próximas. A diminuição na largura da pista secundária, poderá diminuir a mortalidade pois foi a que teve impacto na mortalidade das árvores, além de apresentar maior área aberta.

\section{REFERÊNCIAS}

ALVARES, C. A.; STAPE, J. L.; SENTELHAS, P. C.; GONÇALVES, J. L. M.; SPAROVEK, G.. Köppen's climate classification map for Brazil. Meteorologische Zeitschrift, v.22, p.711-728, 2013.

BRASIL. Lei n.11.284, de 2 de março de 2006. Dispõe sobre a gestão de florestas públicas para a produção sustentável; e dá outras providências. Brasília: DOE, 2006.

CASTRO, M. S. A.; VIANA, A. P. S.; LOBATO, C. C.; MUNIZ, J. L.; LIMA, M. W. S.; MELO, L. O.. Impactos da exploração florestal na estrutura e na composição florística da vegetação remanescente em área manejada na floresta nacional do Tapajós, Belterra, Pará. Agroecossistemas, v.10, n.2, p.125-135, 2018.

CONDÉ, T. M.. Avaliação dos impactos na vegetação após a Exploração Madeireira em Floresta Ombrófila Densa de Terra Firme no Município de Caracaraí/RR. Dissertação (Mestrado em recursos naturais) -Universidade Federal de Roraima, Boa Vista, 2011.

COSTA, D. H. M.; CARVALHO, J. O. P.; SILVA, J. N. M.. Dinâmica da composição florística após a colheita de madeira em uma área de terra firme na Floresta Nacional do Tapajós (PA), Revista de Ciências Agrárias, n.38, 2002.

FERREIRA, F. N.. Análise da sustentabilidade do manejo florestal com base na avaliação de danos causados por exploração de impacto reduzido (EIR) em floresta de terra firme no município de Paragominas-PA. Dissertação (Mestrado em Ciências Florestais) - Universidade Federal Rural da Amazônia, Belém, 2005.

FRANCEZ, L. M. B.; CARVALHO, J. O. P.; BATISTA, F. J., JARDIM F. C. S.; RAMOS, E. M. L. S.. Influência da Exploração Florestal de Impacto Reduzido sobre as Fases de Desenvolvimento de uma Floresta de Terra Firme, Pará, Brasil. Ciência Florestal, v.23, n.4, p.743-753, 2013.

GATTI, R. C.; CASTALDI, S.; LINDSELL, J. A.; COOMES, D. A.; MARCHETTI, M.; MAESANO, M.; PAOLA, A. D.; PAPARELLA, F.; VALENTINI, R.. The impact of selective logging and clearcutting on forest structure, tree diversity and aboveground biomass of African tropical forests. Ecological Research, v.30, n.1, p.119-132, 2015.

GRAAF, N. R.; POELS, R. L. H.; VAN ROMPAEY, R. S. A. R.. Effect of silvicultural treatment on growth and mortality of rainforest in Surinam over long periods. Forest Ecology and Management, v.124, p.123-135, 1999.

HIRAI, E. H.; CARVALHO, C. J. R. D.; SILVA, J. N. M.; CARVALHO, J. O. P. D.; QUEIROZ, W. T.. Efeitos da exploração de impacto reduzido sobre a regeneração natural em uma floresta densa de terra firme no município de Paragominas na Amazônia brasileira. Scientia Forestalis, v.40, n.95, p.306315, 2012.

IBGE. Instituto Brasileiro de Geografia e Estatística. Manual 
Técnico da Vegetação Brasileira. Série Manuais Técnicos em Geociências. 2 ed. Rio de Janeiro, 2012.

LENTINI, M. W.; HOLMES, T. P.; PIRES, I. P.; ZWEEDE, J. C.. Boletim Técnico IFT. Avaliação de Danos e Desperdícios provocados pela Exploração Madeireira em Florestas Amazônicas: um método prático para avaliar a qualidade da exploração. 2015.

MARTINS, S. S.; COUTO, L.; MACHADO, C. C.; SOUZA, A. L.. Efeito da exploração florestal seletiva em uma floresta estacional semidecidual. Revista Árvore, v.27, n.1, p.65-70, 2003.

MARVIN, D. C.; KOH, L. P.; LYNAMC, A. L.; WICH, S.; DAVIES, A. B.; KRISHNAMURTHY, R.; STOKES, E.; STARKEY, R.; ASNER, G. P.. Integrating teehnologies for sealable ecology and conservation. Global Ecology and Conservation, v.7, p.262275, 2016.

NASCIMENTO, R. G. M.; MACHADO, S. A.; FILHO, A. F.; HIGUCHI, N.. Modelagem da sobrevivência, mortalidade e recrutamento de uma floresta na Amazônia Central. Sci. For., Piracicaba, v.41, n.99, p.319-330, 2013.

OLIVEIRA, L. C.. Efeito da exploração da madeira e de diferentes intensidades sobre a dinâmica da vegetação de uma área de $\mathbf{1 3 6}$ ha na floresta nacional do Tapajós. Tese (Doutorado) - Universidade no Aglomeração Urbana de Piracicaba, São Paulo, 2005.

PINTO, A. C. M.. Análise de danos de colheita de madeira em floresta tropical úmida sob regime de manejo florestal sustentado na Amazônia Ocidental. Revista Árvore, v.26, n.4, p.459-466, 2002.

PINTO, A. C.; SOUZA, A. L.; SOUZA, A. P.; MACHADO, C. C.; MINETTE, L. J.; VALE, A. B.. Análise dos danos da exploração de madeira em floresta tropical úmida sob regime de manejo florestal sustentável, na Amazônia Ocidental. Dissertação (Mestrado em Ciência Florestal) - Universidade Federal de Viçosa, Viçosa, 2000.

RODRIGUES, T. E.; SILVA, R. C.; SILVA, J. M. L.; OLIVEIRA JUNIOR, R. C.; GAMA, J. R. N. F.; VALENTE, M. A.. Caracterização e classificação dos solos do município de Paragominas, Estado do Pará. Belém: Embrapa Amazônia Oriental, 2003.

SILVA, J. N. M.; CARVALHO, J. O. P.; LOPES, J. C. A.; ALMEIDA, B. F.; COSTA, D. H. M.; OLIVEIRA, L. C.; VANCLAY, J. K.; SKOVSGAARD, J. P.. Growth and yield of a tropical rain forest in the Brazilian Amazon 13 years after logging. Forest Ecology and Management, v.71, n.3, p.267-274, 1995.

SILVA, P. H. D.; GOMIDE, L. R.; FIGUEIREDO, E. O.; CARVALHO, L. M. T. D.; FERRAZ-FILHO, A. C.. Optimal selective logging regime and log landing location models: a case study in the Amazon forest. Acta Amazônica, v.48, n.1, p.18-27, 2018.

TAFFAREL, M.; GOMES, J. M.; CARVALHO, J. O. P. D.; MELO, L. D. O.; FERREIRA, J. E. R.. Efeito da silvicultura pós-colheita na população de Chrysophyllum lucentifolium Cronquist (goiabão) em uma floresta de terra firme na Amazônia brasileira. Revista Árvore, v.38, n.6, p.1045-1054, 2014.

A CBPC - Companhia Brasileira de Produção Científica (CNPJ: 11.221.422/0001-03) detém os direitos materiais desta publicação. Os direitos referem-se à publicação do trabalho em qualquer parte do mundo, incluindo os direitos às renovações, expansões e disseminações da contribuição, bem como outros direitos subsidiários. Todos os trabalhos publicados eletronicamente poderão posteriormente ser publicados em coletâneas impressas sob coordenação da Sustenere Publishing, da Companhia Brasileira de Produção Científica e seus parceiros autorizados. Os (as) autores (as) preservam os direitos autorais, mas não têm permissão para a publicação da contribuição em outro meio, impresso ou digital, em português ou em tradução. 